\title{
CONCEITOS DE LEITURA DE PROFESSORES EM FORMAÇÃO INICIAL: UM ESTUDO DE CASO
}

\author{
Tânia Maria Moreira
}

\section{RESUMO}

É sabido que as dificuldades de leitura apresentadas pelos alunos têm sua origem em fatores de diferentes ordens, tais como: social, econômico, político e educacional; e que o caminho para solucionar o problema consiste em desenvolver ações e pesquisas sobre esses fatores. Em um estudo realizado procurou-se centrar a atenção em questões educacionais, mais especificamente sobre a formação de conceitos de leitura de acadêmicos em formação. Neste trabalho, desenvolveu-se uma experiência pedagógica com o objetivo de investigar e descrever os processos cognitivos e eventuais evoluções na formação de conceitos de leitura de acadêmicos-estagiários de língua materna, do Curso de Letras da UFSM, a partir de registros retrospectivos e prospectivos revelados em diários.

\section{INTRODUÇÃO}

Avaliações realizadas pelo Programa Internacional de Avaliação de Alunos (PISA), assim como pela Organização das Nações Unidas para a Educação e Cultura (UNESCO) em conjunto com a Organização para a Cooperação e Desenvolvimento Econômico (OCDE) revelam que, na educação brasileira, a leitura ainda é um problema a ser resolvido. Embora não se conheça o teor de tais avaliações, os resultados apresentados são preocupantes e recomendam que, no mínimo, reflita-se sobre o caso.

Por outro lado, sabe-se que as dificuldades de leitura apresentadas pelos alunos têm sua origem em fatores de diferentes ordens, tais como: social, econômico, político e educacional; e que o caminho para solucionar o problema consiste em desenvolver ações e pesquisas sobre esses fatores. Em um estudo realizado procurou-se centrar a atenção em questões educacionais, mais especificamente sobre a formação de conceitos de leitura de acadêmicos em formação. Neste trabalho, desenvolveu-se uma experiência pedagógica com o objetivo de investigar e descrever os processos cognitivos e eventuais evoluções na formação de conceitos de leitura de acadêmicos-estagiários de língua materna, do Curso de Letras da UFSM, a partir de registros retrospectivos e prospectivos revelados em diários.

Neste artigo, pretende-se descrever as ações realizadas no estudo e os resultados obtidos. Inicialmente, relacionar-se-á as questões problematizadoras que 
nortearam as ações dos pesquisadores e os objetivos específicos decorrentes destes problemas; em seguida, descrever-se-á as três etapas vivenciadas no estudo e, por último, as considerações e conclusões a que se chegou diante dos resultados obtidos.

\section{QUESTÕES PROBLEMATIZADORAS E OBJETIVOS ESPECÍFICOS DA PESQUISA}

Com base no objetivo geral apresentado na introdução deste artigo, desencadearam-se três questionamentos que acompanharam toda a pesquisa realizada: a) Como organizar uma proposta de trabalho em que todos os envolvidos no contexto de aprendizagem de formação inicial de Língua Portuguesa se sintam engajados e livres para manifestar seus conceitos, suas crenças?; b) Como identificar e interpretar os processos cognitivos desenvolvidos por futuros professores na formação de conceitos de leitura e suas eventuais maturações conceituais? e c) Quais os modelos teóricos que sustentam as concepções e crenças de futuros professores (estagiários) quanto ao processo de ensino-aprendizagem de leitura?

Estas questões, por sua vez, deram origem a três objetivos específicos. Com relação ao primeiro problema, teve-se como objetivo implementar, experimentalmente, uma "disciplina - projeto", no curso de formação inicial de professores de Letras, que favoreça a reflexão de concepções e crenças dos acadêmicos e a construção de novas possibilidades de aulas de Língua Materna a partir de problemas reais experimentados no contato com alunos da Educação Básica. Em decorrência dos outros dois problemas, teve-se como objetivos analisar, descrever e interpretar os processos cognitivos desenvolvidos por dois professores em formação inicial, nas suas reflexões prospectivas e retrospectivas quanto à formação de conceitos de leitura e investigar os processos cognitivos desenvolvidos por futuros professores no que tange à sofisticação dos conceitos de leitura segundo a teoria vygotskyana.

Para atingir os objetivos e tentar encontrar respostas para os questionamentos, desenvolveu-se, em um primeiro momento, estudos bibliográficos, em seguida, implementou-se uma experiência pedagógica e por último realizou-se um estudo de caso. 


\section{ETAPAS VIVENCIADAS NA PESQUISA}

\subsection{LEVANTAMENTOS BIBLIOGRÁFICOS}

Na primeira etapa do trabalho, buscaram-se estudos e referências teóricas sobre formação de professores, formação de conceitos, conceitos de leitura, metodologias adotadas nos cursos de formação de professores e modelos usados para analisar e interpretar os conceitos de leitura apresentados pelos acadêmicos.

Sobre a formação de professores (cultura de ensinar/aprender -paradigmas sócio-culturais), a busca pautou-se por teorias de Freire, Bateson, Morin e Vygotsky. Com relação à formação de conceitos / teorias e crenças, o apoio incidiu nos estudos de Vygotsky, Kohl de Oliveira, Gee e D'Andrade. Os modelos teóricos de leitura basearam-se em Freire, Kleiman, Coracini, Zappone e Gee, a fim de fazer-se um estudo exploratório e não-dogmático sobre o conceito de leitura. Por último, no tocante aos modelos metodológicos, para elaborar o projeto-disciplina, foram utilizadas as pesquisas de Serrano, Carr \& Kemmis, Burns, que versam sobre Pesquisa-ação. Finalmente, no estudo de caso realizado, foi necessário lançar mão do Paradigma Indiciário de Ginzburg.

Na segunda etapa do trabalho de dissertação, implementou-se uma proposta de ação denominada Projeto-disciplina, a qual teve como proposta metodológica a pesquisa-ação.

\subsection{IMPLEMENTANDO O PROJETO-DISCIPLINA}

Esta experiência foi desenvolvida de setembro de 2002 até fevereiro de 2003, tendo como sujeito 52 acadêmicos do VIII semestre do Curso de Letras que realizaram atividades coletivas e individuais. Desse total, 28 deles fizeram parte de uma turma e 24 de outra. Cada turma totalizou 40 encontros, compreendendo ao todo 60 horas aulas de trabalho. Nesse período, foram organizados, nas duas turmas, quatorze grupos de trabalho foram organizados e em cada um foi desenvolvido um projeto de pesquisa-ação. Assim, grupo por grupo sistematizou um relatório por etapa realizada, totalizando, no final do projeto 03 relatórios. Também foram realizadas atividades individuais onde cada aluno produziu o seu diário nos diferentes momentos do projeto, 
totalizando, no final 03 diários. Entre as duas turmas, 42 relatórios e 156 diários foram produzidos ao término da disciplina.

Do total de acadêmicos participantes do projeto, alguns não tinham nenhuma experiência de sala de aula, como professores; outros já atuavam em escolas públicas; e havia, ainda, acadêmicos que se encontravam no período de estágio (ora desenvolvendo aulas, ora em período de observação ou em ambos os casos).

Foi então implementada a pesquisa-ação. Para caracterizar a adoção da pesquisa-ação como metodologia de trabalho, de acordo com Carr \& Kemmis, três condições mínimas são necessárias:

1. que um projeto seja planejado com o tema da prática social;

2. que tal projeto recorra a uma espiral de elos de planejamento, ação, observação e reflexão, estando todas essas atividades implantadas e interrelacionadas sistematicamente e autocriticamente;

3. que envolva os responsáveis da prática em todos os momentos e em cada uma das atividades, ampliando gradualmente a participação no projeto para incluir os outros afetados pela prática, e manter um controle colaborativo do processo.

Burns, contrapondo-se, em alguns aspectos, às idéias de Carr \& Kemmis, afirma que a pesquisa-ação não se processa em um ciclo, ou em uma seqüência de ciclos, mas em uma série de experiências inter-relacionadas que auxiliam os envolvidos a refletir, retrospectiva e prospectivamente, sobre suas ações em face de problemas vivenciados em contexto real.

Desse modo, a pesquisa-ação passa a ser concebida como abordagem de trabalho, ou seja, como um conjunto de procedimentos usados para gerar os dados em uma investigação.

$\mathrm{Na}$ organização da proposta de ação, desenvolvida no Curso de Letras, as ponderações de Burns foram consideradas e concebeu-se o projeto-disciplina em três momentos. Nestes, os acadêmicos passaram por estágios de observação de práticas pedagógicas, de desenvolvimento de ações e reflexões sobre as ações e de planejamento de ações possíveis de serem desenvolvidas em uma nova prática pedagógica. 
Nesta fase, desenvolveu-se um conjunto de procedimentos, conforme constam no quadro abaixo, para gerar dados que possibilitassem, de um lado, a realização de reflexões retrospectivas e prospectivas, por parte dos orientadores da disciplina e dos alunos do VIII semestre do curso de Letras da UFSM, sobre ações realizadas em face de um problema real de sala de aula presenciado no estágio, ou a partir de produções de alunos de um curso pré-vestibular; e, de outro, o acompanhamento, análise e interpretação dos modelos mentais e conceituais desenvolvidos pelos acadêmicos e suas eventuais evoluções cognitivas sobre leitura.

\begin{tabular}{|c|c|c|}
\hline 19 Momento & 20 Momento & 3o Momento \\
\hline $\begin{array}{l}\text { "Reflexão sobre a } \\
\text { experiência didática e } \\
\text { tentativa de diagnóstico } \\
\text { de problemas" }\end{array}$ & $\begin{array}{l}\text { "Hipótese de ação a partir } \\
\text { da experiência didática" }\end{array}$ & $\begin{array}{l}\text { "Projeto de intervenção } \\
\text { didática" }\end{array}$ \\
\hline $\begin{array}{l}\text { OBJETIVOS } \\
\text { Identificar três problemas } \\
\text { de sala de aula, } \\
\text { detectados durante o } \\
\text { estágio supervisionado ou } \\
\text { nas produções de alunos } \\
\text { do curso pré-vestibular, e } \\
\text { selecionar o mais } \\
\text { relevante. }\end{array}$ & $\begin{array}{l}\text { Levantar hipóteses e } \\
\text { especulações sobre o } \\
\text { tema de estudo visando } \\
\text { corrigir ou atenuar o } \\
\text { problema diagnosticado. }\end{array}$ & $\begin{array}{l}\text { Produzir atividades } \\
\text { didáticas a partir de } \\
\text { reflexões levadas a efeito } \\
\text { sobre os contextos } \\
\text { educativos analisados } \\
\text { nas fases anteriores. }\end{array}$ \\
\hline $\begin{array}{l}\text { ATIVIDADES } \\
\text { Projeto de estudo - em } \\
\text { grupo: } \\
\text { 1. relato individual e oral } \\
\text { de três problemas - } \\
\text { formação de grupos de } \\
\text { pesquisa-ação por tema } \\
\text { de interesse, } \\
\text { 2. levantamento de } \\
\text { questionamentos e } \\
\text { certezas sobre o tema. }\end{array}$ & $\begin{array}{l}\text { Ações colaborativas e } \\
\text { produção em grupo: } \\
\text { 1. seleção e coleta de } \\
\text { suporte teórico, para } \\
\text { efetivar a pesquisa-ação, } \\
\text { a maturação consciente e } \\
\text { aprimoramento de } \\
\text { conceitos, } \\
\text { 2. elaboração de relatório } \\
\text { contendo as teorias }\end{array}$ & $\begin{array}{l}\text { Orientação por grupo - } \\
\text { questionamentos sobre } \\
\text { depoimentos apresentado } \\
\text { nos relatórios } 01 \text { e } 02 \text {, } \\
\text { visando a discutir e } \\
\text { aprimorar as informações } \\
\text { registradas em tais } \\
\text { documentos. } \\
\text { Oficinas temáticas - } \\
\text { Projetos de propostas de } \\
\text { ação em grupo. }\end{array}$ \\
\hline
\end{tabular}




\begin{tabular}{|l|l|l|}
\hline $\begin{array}{l}\text { 3. busca cooperativa de } \\
\text { informações }\end{array}$ & $\begin{array}{l}\text { estudadas, conforme o } \\
\text { problema do grupo. } \\
\text { Produção Autônoma - } \\
\text { diários contendo reflexões } \\
\text { teóricas }\end{array}$ & $\begin{array}{l}\text { Produção Autônoma - } \\
\text { diários }\end{array}$ \\
$\begin{array}{l}\text { Produção autônoma - } \\
\text { diários - Seminários e } \\
\text { debates }\end{array}$ & $\begin{array}{l}\text { auto-avaliação do } \\
\text { desenvolvimento } \\
\text { cognitivo, considerando } \\
\text { os diferentes percursos } \\
\text { trilhados, avanços } \\
\text { conceituais obtido e } \\
\text { avaliação crítica da } \\
\text { "disciplina - projeto" } \\
\text { Trabalho de conclusão - } \\
\text { Comunicação oral e } \\
\text { publicação on-line. }\end{array}$ \\
\hline
\end{tabular}

\subsection{ESTUDO DE CASO}

$\mathrm{Na}$ terceira etapa da pesquisa, desenvolveu-se um estudo de caso onde se analisaram dados produzidos por um dos grupos formado. Este grupo foi composto por dois sujeitos, doravante denominados $\mathrm{G}$ e M, e envolveu a análise de seis diários e três relatórios. Como critérios para a seleção do corpus desse estudo, identificouse: 1) quais os grupos que abordaram o tema leitura nos projetos e 2) quais as produções dotadas de singularidades, surpreendentes quanto as crenças e conceitos de leitura - consoante com o modelo de análise empregado.

Durante a análise das crenças e o desenvolvimento cognitivo e conceitual dos alunos, não se teve como intenção criar modelos genéricos de desenvolvimento conceituais de leitura de futuros professores, nem tampouco rotular a dupla de aprendizes observada, mas sim, descobrir como reconstruir modelos mentais e interpretá-los para iluminar outros contextos de estudos que adotam, como instrumento de análise de dados, o uso de diários e relatórios com o objetivo de acompanhar e melhor compreender os processos cognitivos e evoluções conceituais de aprendizes. Para proceder-se a análise dos dados adotou-se como referência o modelo indiciário e o modelo da mente comum de D’Andrade modificado, que passamos a elucidar brevemente.

Paradigma Indiciário é uma abordagem qualitativa que, conforme Ginzburg (1989), encontra suas raízes por volta do final do século XIX, quando o homem, para 
sobreviver, precisou desenvolver certas habilidades. No século XX, esse paradigma começou a se firmar como um modelo científico nas ciências humanas, mantendo uma estreita relação com técnicas empregadas na crítica de arte, na psicanálise e na investigação social. Pode-se dizer, portanto, que o paradigma indiciário consiste em "observar os pequenos fatos, dos quais podem depender as inferências mais amplas. Não confiar nas impressões gerais, mas concentrar-se nos pormenores." (Eco \& Sebeok 1991, p. 30).

Para Peirce (apud Eco \& Sebeok, 1991, p. 02) há três tipos de raciocínio nesse paradigma: abdução, dedução e indução. A abdução adota uma hipótese ou proposição que conduz a uma predição daquilo que parece ser surpreendente. A dedução é o procedimento pelo qual as conseqüências experienciais de nossa hipótese são investigadas. A indução trata de testar experimentalmente a hipótese para confirmá-la ou refutá-la.

Para interpretar os diários produzidos, atentou-se para as pistas deixadas pelos autores em seus diários e seguiu-se o modelo da mente comum proposto por D’Andrade.O modelo, após aperfeiçoamento por Richter, se revelou eficiente para ler reflexivamente diários, pois permite a identificação de um estado ou de um processo mental. Esse modelo, que aqui apresentamos já modificado, incorpora os seguintes parâmetros cognitivos: percepção, crenças, sentimentos, desejos, que se subdividem em intenção/injunção e planejamento.

A percepção é influenciada pela crença (esquemas culturais e teorias) ao mesmo tempo que a revela. A crença, alimentada pelo sentimento (e vice-versa) ao incidir sobre determinado estado de coisas, como um descompasso da crença em relação à conduta ou ação, provoca a necessidade de suprir essa ruptura surgindo então um desejo. Este desejo é, portanto, fruto da cultura, da imaginação, das identificações que possuem laços tênues com a realidade e apresentam uma intencionalidade de construir um sentido ou uma proposta de reformulação conceitual. O desejo se desdobra em intenção ou injunção (querer, precisar ou dever) que depende de condições favoráveis. O querer difere do desejar por buscar um investimento objetal da cultura vigente, isto é, apossar-se de objetos (coisas, imagens, valores, referentes culturais) aprisionados no passado ou projetados para o futuro. Pode ser um querer próprio (do ego), por delegação (querer do outro) ou um querer por inovação ou busca. Essa intenção ou injunção possui laços fortes com o mundo 
real, com a verossimilhança. $O$ desejo tenta concretizar uma ação, a qual passa por um planejamento, que é a antecipação da relação meio/fim e depende da volição. Ao planejar uma ação ou conduta, a decisão e o autocontrole são fatores relevantes.

Com base nesses dois modelos, definiram-se procedimentos para análise de caso. No primeiro momento, fez-se um recorte panorâmico no material coletado e, posteriormente, realizou-se uma análise objetiva dos dados coletados.

a) Visão panorâmica - Fez-se um levantamento e análise sintética das regularidades lingüísticas empregadas nos diários (observação /análise, a ação, reflexão - projeções) para analisar as percepções, crenças, sentimentos, construções imaginárias, desejos, injunções e condutas sobre a cultura de ensinar e aprender leitura em sala de aula.

b) Visão objetiva - Descreveu-se e interpretou-se, longitudinal e transversalmente, os caminhos percorridos pelos sujeitos $G$ e $M$ para construir conceitos de leitura (possível origem das crenças, os modelos mentais desenvolvidos - resistências, restaurações de crenças e as evoluções cognitivas apresentadas).

\section{CONSIDERAÇÕES FINAIS}

\subsection{SOBRE O PROJETO-DISCIPLINA}

Os dados sugerem que os alunos do VIII semestre:

- não haviam participado, em outros momentos do curso de Letras, de nenhuma outra proposta pedagógica na linha de pesquisa-ação, embora esta metodologia estivesse sendo muito valorizada e discutida nos meios acadêmicos em geral. Por isso, parecem ter-se sentido em meio a um enorme caos quando os desafios de trabalho Ihes foram apresentados. Isso pôde transparecer, por exemplo, pelo modo como os alunos resolveram os problemas frente aos referidos desafios durante o semestre na disciplina,

- aos poucos, se envolveram nas pesquisas, passaram não só a teorizar sobre o que acreditavam, assim como atuar e refletir sobre suas ações, mas também 
sobre as ações e reações dos alunos, e ainda a organizar os conhecimentos, a fazer constatações, apresentar algumas evoluções e

- demonstraram certa facilidade para detectar problemas de aprendizagem nas experiências práticas realizadas, mas deram a entender que precisam aprender a identificar melhor suas crenças e melhorar a qualidade de reflexões para alimentar o nível do saber sobre o saber e o do saber sobre o saber-fazer;

Os resultados são, ainda, sugestivos de que a abordagem adotada permitiu aos envolvidos no processo desenvolverem habilidades de:

- raciocínio,

- investigação,

- formação de conceitos,

- interpretação e explicação (tradução) ao tentarem solucionar ou minimizar um problema observado.

Estas quatro habilidades provavelmente fizeram com que os participantes da pesquisa passassem a:

- observar problemas reais;

- elaborar perguntas sobre os problemas, revelar crenças, neste caso, sobre leitura;

- refletir, com base em dados observados, sobre os resultados obtidos; fazer auto-avaliações e pesquisas;

- estabelecer relações de idéias,

- identificar pressuposições; apresentar explicações;

- formular conceitos,

- sistematizar idéias e crenças; produzir conclusões, e

- projetar novas ações.

\subsection{SOBRE O "DESIGN" DE ESTUDO DE CASO}

O paradigma indiciário e o modelo da mente comum de D'Andrade modificado: 
- revelaram-se suportes eficientes na análise dos dados, pois foi possível mapear e acompanhar os processos mentais e o desenvolvimento conceitual de leitura da dupla de alunos no nível do saber e do saber-fazer. Porém, a adoção dos modelos mencionados para acompanhar um número maior de produções escritas, em um curso que privilegia a linha sócio-interacionista e adota uma abordagem de pesquisa-ação, visando detectar e acompanhar as evoluções conceituais dos alunos em todos os momentos da pesquisa, exige um trabalho em equipe, porque descobrir o modelo mental e conceitual de alguém não é uma atividade de fácil execução, pois todas as crenças de uma pessoa não estão disponíveis para análise em uma única situação.

- exigiram do pesquisador-orientador o desenvolvimento de um trabalho de lógica e de leitura enquanto ato discursivo para interagir com o docente em formação, a fim de que este pudesse refletir sobre as próprias concepções teóricas e práticas.

\subsection{SOBRE A CULTURA DE ENSINAR DOS SUJEITOS DA PESQUISA}

Diante dos desafios da sala de aula, enquanto atuavam ou apresentavam ações pedagógicas ligadas à concepção de leitura, os futuros professores mostraram refluxo às suas crenças arraigadas, oriundas da cultura tradicional de ensinar e aprender. Indiciou-se:

- teoricamente, que eles apresentavam uma preocupação com a aprendizagem dos seus alunos de estágio, e com a interação na sala de aula,

- na prática, que eles não conseguiram estabelecer uma interação efetiva, trocas e confrontos de idéias entre professor-aluno, aluno-professor, e aluno-aluno a fim de que novos conhecimentos, novos conceitos fossem construídos e reconstruídos, a partir de uma proposta de trabalho intercultural, que respeitasse as individualidades,

- que os acadêmicos deixavam transparecer uma preocupação em passar informações aos alunos de estágio, sem que estes sentissem a importância e/ou necessidade delas; 
- que os professores em formação, apesar das atividades formativas na disciplina, persistiram na crença tradicional de que é função do professor antecipar todos os desdobramentos de uma proposta de aula padrão de leitura para todos os seus alunos e objetivar um resultado uniforme para seus alunos, independente das diferenças culturais de cada um destes.

\subsection{SOBRE O CONCEITO DE LEITURA}

Há indícios de que:

- o modelo mental elaborado subjetivamente pela dupla de acadêmicas está fortemente ligado à linha teórica estruturalista ou de decodificação, nas conceituações de Zappone e Coracini;

- contrastivamente, $\mathrm{G}$, ao término da experiência, manifestou uma tendência a incluir nas suas crenças outras relacionadas ao modelo interacionista de leitura, enquanto $M$ manifestou, desde $o$ início dos trabalhos, uma tendência a apresentar um conceito de leitura com influência da versão do modelo interacionista bastante em voga nos anos 70 e 80 .

\subsection{SOBRE OS MODELOS MENTAIS}

Os sujeitos:

- revelaram-se resistentes às iniciativas de desfragmentação das crenças, na medida em que não manifestaram em seus diários indícios da construção de uma rede teórica consistente de conceitos;

- em um semestre letivo, fizeram pequenos avanços que se caracterizaram, seja por acrescentar informações novas às suas antigas crenças adquiridas, inconscientemente, pela cultura de aprender leitura, seja por suprimir aspectos, fazendo apagamentos de informações importantes dos modelos teóricos.

Assim sendo, a pesquisa realizada aponta significativamente para a conclusão de que possíveis transformações paradigmáticas relacionadas à cultura de ensinar / aprender e quanto aos conceitos de leitura: 
- dependem de mudanças de crenças, de conceitos. Isso demanda competência do professor-orientador em mapear o circuito reflexivo do aluno, e estabelecer interações com qualidade em sala de aula, de modo que os aprendizes reconheçam suas crenças e consigam fazer abstrações reflexivas e projetar mudanças, tempo para que o aluno passe por diferentes estágios de formação de conceitos, conforme postula Vygotsky e do uso de métodos adequados durante todo o trabalho; $\mathrm{e}$

- podem acontecer mediante um trabalho de formação continuada de professores, formação esta que relacione teoria e prática e com a produção de metáforas.

Uma das limitações desta pesquisa relaciona-se à carência, até o momento, de um modelo científico para nortear a interação entre professor-orientador e professor em formação, depois de o professor-orientador ter um "raio-X" do modelo mental construído pelos acadêmicos sobre o conceito de leitura, assim como uma proposta de ação que explore a construção de analogias pelo aluno.

Além disso, o trabalho assinala a necessidade de que sejam desenvolvidos, também, cursos para professores já formados, de modo que estes repensem seus conceitos de leitura e possam projetar ações multiplicadoras que colaborem no sentido de reverter os números preocupantes sobre a leitura no Brasil.

\section{BIBLIOGRAFIA}

D'ANDRADE, R. (1987) A folk model of mind. In: HOLLAND, D. \& QUINN, N. Cultural Models in Language \& Thought. Cambridge: Cambridge University Press, 1995. p.112-148.

ECO, U. \& SEBEOK, T. A. (orgs.) O signo de três. São Paulo: Perspectiva, 1991.

GINZBURG, C. Sinais: raízes de um paradigma indiciário. In: Mitos, emblemas, sinais: morfologia e historia. São Paulo: Companhia das Letras, 1989. 
CARR, Wilfred \& KEMMIS, Stephen. Becoming critical: education, knowledge and action research. Deakin University Press, 1986. 